John J. Marini

\title{
Lower tidal volumes for everyone: principle or prescription?
}

Received: 31 October 2012

Accepted: 1 November 2012

Published online: 21 November 2012

(C) Springer-Verlag Berlin Heidelberg and ESICM 2012

This editorial refers to the article available at: doi:10.1007/s00134-012-2728-4.

J. J. Marini (®)

University of Minnesota, Minneapolis/St. Paul, 640 Jackson Street, St. Paul, MN, USA

e-mail: john.j.marini@healthpartners.com

As demonstrated by the persuasive essay by Lellouche and Lipes [1] appearing in this issue, an attractive argument can be made for using relatively low tidal volumes in all ventilated patients at risk of ARDS. It is hard to quibble with the intent or rationale-after all, in any given individual, tidal volume is achieved by driving pressure, a key component of the VILI equation. Moreover, no safe threshold for tidal volume has yet been identified in clinical trials of ALI/ARDS management [2], and because targeting lower tidal volumes seems to reduce the incidence of adverse outcomes [3, 4], 'low' tidal volumes should be applied to all ventilated patients potentially at risk. Sounds very reasonable-what is there not to like?

Unfortunately, the best of intentions can be complicated by inconvenient truth. Simple guidelines may set a good management direction and starting point, but may not be necessary or feasible in every case. Let us take these concerns one at a time-'necessary' first. Investigations into the causative relationships among diverse mechanical forces, machine settings, and cofactors that impact VILI continue to the present day. It is generally understood, however, that the damage resulting from higher tidal volume relates to forces developed at the level of the terminal airways and alveoli. Repeated application of peak trans-alveolar pressures and tidal swings of alveolar pressure that markedly exceed those encountered during normal tidal breathing will eventually give rise to hemorrhagic edema and inflammation that mimic ARDS. But larger tidal volumes develop damaging stresses only when the capacity of the aerated and recruitable compartments is insufficient to accept them without excessive strain. It has been estimated that pressure incursions into dangerous territory begin only when the breath nearly doubles the volume of the resting aerated compartment [5]. Trans-alveolar pressure is a function of that ratio. In theory, then, we have two options to rationally set tidal volume and PEEP in challenging cases: measure resting lung volume, measure trans-alveolar pressure, or both. Thus, the inadvisability of using a larger tidal volume depends not on a formula of expected healthy lung size, but rather by the actual size of the baby, juvenile, or adult lung associated with it.

In healthy, mechanically homogeneous lungs, enormous tidal volumes are required to produce lungdamaging forces. For example, marathon athletes may repeatedly take breaths exceeding $21(>20 \mathrm{ml} / \mathrm{kg})$ for hours on end without apparent problems afterward. Patients at risk of ARDS may be predisposed to injurious responses to considerably lower tidal volumes by reduced aerated reservoir (functional residual capacity, FRC), stress focusing at points of mechanical heterogeneity [6], and by tissues primed for inflammation by the first hit of their underlying disease [7, 8]. Yet, until the airspace begins to flood or consolidate, the aeratable space is seldom reduced by more than half, and when precautions are taken to avoid fully horizontal positioning and to apply modest PEEP, tidal re-opening and closure risk is reduced considerably. The point here is that for many patients the actual forces encountered during deep breathing are well tolerated, at least as judged by the transpulmonary pressure generated by the ratio of the stressing volume (set by 
the tidal volume and PEEP combination) to the resting FRC. The bottom line is that although relatively low tidal volumes are usually safer, they are not always necessary.

What about the second concern of 'feasibility'? Monotonous tidal volumes are seldom encountered in nature; variation of VT is the rule. Periodic deep breaths, or sighs - two to three times normal-are frequently taken by healthy subjects who breathe with tidal volumes that average $\sim 6 \mathrm{ml} / \mathrm{kg}$. The afferent limb of the sighing reflex may be debatable, but one function of periodic deep breathing seems to be maintaining recruitment of dependent lung units [9]. Enforcing consistently small tidal volumes (without sighs) eventually provokes dyspnea $[10$, 11]. When using monotonous but relatively large tidal volumes, the need to sigh is all but eliminated. Such observations regarding comfort and sighs were the original motivation for adopting large tidal volumes in the early days of ventilation with positive pressure [12]. In pre-injured lungs, persistently small tidal volumes have been shown to be associated with lower oxygenation and reduced compliance [13, 14], presumably due to advancing atelectasis. If so, the number of 'stress risers' may actually increase [6]. As pointed out by Lellouche and Lipes [1], providing enough PEEP may forestall atelectasis, and perhaps the discomfort associated with unremitting inflations with low tidal volumes-but this remains to be shown.

What seems clear from clinical experience is that imposing small tidal volumes tends to generate the need for deeper sedation, even when minute ventilation is maintained constant by raising breathing frequency. Deep sedation carries with it a raft of associated problems that are best avoided [15]. Parenthetically, when opiates are used in the comforting regimen, any given minute ventilation tends to be met by a reduced frequency but higher tidal volumes. It is concerning that the ultimate in low tidal volume application, high frequency oscillation (a technique that requires deep sedation for lengthy periods) has not been shown to confer outcome advantage, and at least one well designed and very recently completed clinical trial suggests the opposite.

The feasibility problem is compounded by high ventilatory demands. Sepsis, metabolic acidosis, pain, and agitation may cause minute ventilation to rise two- to fourfold. Attempting to hold tidal volumes to $6 \mathrm{ml} / \mathrm{kg}$ obligates either a dramatic compensatory increase in breathing frequency or the acceptance of permissive hypercapnia and deeper sedation. Simple guidelines such as $6 \mathrm{ml} / \mathrm{kg}$ pbw (predicted body weight) adjust well enough for problems of obesity and nutritional status. However, unless tidal volume is also scaled to the minute ventilation requirement, respiratory rate may be forced into an intolerable range. For example, the need for $12 \mathrm{l} / \mathrm{min}$ ventilation is met with a breathing frequency of 25 breaths $/ \mathrm{min}$ in an $80 \mathrm{~kg}$ patient (tidal volume $480 \mathrm{ml}$ ). But using the same $6 \mathrm{ml} / \mathrm{kg}$ formula, 40 breaths $/ \mathrm{min}$ would be needed to meet that same $12 \mathrm{l} / \mathrm{min}$ in a lean subject weighing $50 \mathrm{~kg}(\mathrm{VT}=300 \mathrm{ml})$. Without constraining minute ventilation or increasing VT, the respiratory rate would rise to an unsustainable level. Extra-pulmonary gas exchange, which reduces ventilation requirement, may someday offer a solution to this conundrum.

I am in full agreement with Lellouche and Lipes [1] that for anyone, reducing tidal volume will simultaneously ease driving pressure, and (assuming atelectasis can be averted) associated mechanical stresses within the lung. In some instances when ventilating pressures are high, doing so should offer prophylactic benefit. But in our enthusiasm for lung protection, let us not go too far. Because formulas based on predicted body weight do not account for the actual size of the aerated space nor address feasibility issues, we should not confuse a broadly useful guideline with a prescription for all. Caution is especially prudent when extending an observation drawn from clinical trials of lung injury to healthier populations with greater reserve or to patients with high and irremediable ventilation demands. Numerical guidelines must be adjusted to accord with inconvenient physiologic realities.

\section{References}

1. Lellouche F, Lipes J (2013)

Prophylactic protective ventilation: lower tidal volumes for all critically ill patients? Intensive Care Med. doi: 10.1007/s00134-012-2728-4

2. Hager DN, Krishnan JA, Hayden DL, Brower RG, ARDS Clinical Trials Network (2005) Tidal volume reduction in patients with acute lung injury when plateau pressures are not high. Am J Respir Crit Care Med 172:1241-1245
3. The Acute Respiratory Distress Syndrome Network (2000) Ventilation with lower tidal volumes as compared with traditional tidal volumes for acute lung injury and the acute respiratory distress syndrome. N Engl J Med 342:1301-1308

4. Gajic O, Frutos-Vivar F, Esteban A, Hubmayr RD, Anzueto A (2005) Ventilator settings as a risk factor for acute respiratory distress syndrome in mechanically ventilated patients. Intensive Care Med 31:922-926
5. Protti A, Cressoni M, Santini A, Langer T, Mietto C, Febres D, Chierichetti M, Coppola S, Conte G, Gatti S, Leopardi O, Masson S, Lombardi L, Lazzerini M, Rampoldi E, Cadringher P, Gattinoni L (2011) Lung stress and strain during mechanical ventilation: any safe threshold? Am J Respir Crit Care Med 183:1354-1362

6. Gattinoni L, Carlesso E, Caironi P (2012) Stress and strain within the lung. Curr Opin Crit Care 18:42-47 
7. Rabinovici R, Bugelski PJ, Esser KM, Hillegass LM, Vernick J, Feuerstein G (1993) ARDS-like lung injury produced by endotoxin in platelet-activating factor-primed rats. J Appl Physiol 74:1791-1802

8. Rotstein OD (2003) Modeling the twohit hypothesis for evaluating strategies to prevent organ injury after shock/ resuscitation. J Trauma 54(5 Suppl):S203-S206

9. Bendixen HH, Smith GM, Mead J (1964) Pattern of ventilation in young adults. J Appl Physiol 19:195-198

10. Manning HL, Shea SA, Schwartzstein RM, Lansing RW, Brown R, Banzett RB (1992) Reduced tidal volume increases "air hunger" at fixed $\mathrm{PCO}_{2}$ in ventilated quadriplegics. Respir Physiol 90:19-30
11. Harty HR, Mummery CJ, Adams L, Banzett RB, Wright IG, Banner NR, Yacoub MH, Guz A (1996) Ventilatory relief of the sensation of the urge to breathe in humans: are pulmonary receptors important? J Physiol 490:805-815

12. Housley E, Louzada N, Becklake MR (1970) To sigh or not to sigh? Am Rev Respir Dis 101:611-614

13. Suter PM, Fairley HB, Isenberg MD (1978) Effect of tidal volume and positive end-expiratory pressure on compliance during mechanical ventilation. Chest 73:158-162
14. Bendixen HH, Hedley-Whyte J, Laver MB (1963) Impaired oxygenation in surgical patients during general anesthesia with controlled ventilation. A concept of atelectasis. N Engl J Med 269:991-996

15. Jakob SM, Ruokonen E, Grounds RM, Sarapohja T, Garratt C, Pocock SJ, Bratty JR, Takala J, Dexmedetomidine for Long-Term Sedation Investigators (2012) Dexmedetomidine vs midazolam or propofol for sedation during prolonged mechanical ventilation: two randomized controlled trials. JAMA 307:1151-1160 